\title{
Analysing knowledge building: usages, achievements and limits of forums at university ${ }^{1}$
}

\author{
Noemí Verdú Surroca \\ Teaching Innovation and E-learning Area \\ Educational Sciences Institute - Life-Long Learning \\ University of Lleida \\ Jaume II, 71, 25001, Lleida, Spain \\ Fax: +34 973703377 \\ E-mail:nverdu@ice.udl.cat
}

\author{
Jaume Sanuy Burgués \\ Pedagogy and Psychology Department, \\ University of Lleida \\ Avda. Estudi General, 4, 25003, Lleida, Spain \\ E-mail: sanuy@pip.udl.cat
}

\begin{abstract}
This paper aims to explore asynchronous communication in computer supported collaborative learning (CSCL). Thirty virtual forums are analysed in both a quantitative and a qualitative way. Quantitatively, the number of messages written, message threads and original and answer messages are counted. Qualitatively, the content of the notes is analysed, cataloguing these into two different levels: on the one hand, as a set of knowledge building process categories, and on the other hand, following the scaffolds that Knowledge Forum offers. The results show that both an exchange of information and a collaborative work take place. Nevertheless, the construction of knowledge is superficial.
\end{abstract}

Keywords - Computer Supported Collaborative Learning (CSCL), interaction analysis, content analysis, virtual forums, knowledge building.

Biographical notes: Noemí Verdú works as a psychopedagogist in the Teaching Innovation and E-learning Area in the Educational Sciences Institute at University of Lleida and as a professor of the Culture, Science and Technology Senior Degree (UdL). Doctor in Psychopedagogy by UdL, Bachelor in Primary Education (1998) and Bachelor in Psychopedagogy (2001), by the Universitat de Lleida, in 2006 she worked as a cover teacher in the Faculty of Educational Sciences and she continued to teach in the same faculty during the academic year 2008-09. Recently, she has defended her PhD research, about collaborative learning in teaching and learning via virtual environments in higher education.

Jaume Sanuy Burgués is a senior Lecturer in Educational Psychology, Department of Psychology and Pedagogy, Faculty of Education. Doctor in Psychology by the Universitat de

\footnotetext{
${ }^{1}$ a shorter version of this work is published in the IASK - Teaching and Learning Conference 2010.
} 
Barcelona,1988, he began his research in the Department Sciences and Behaviour Methodology at Universitat de Barcelona. He wrote his $\mathrm{PhD}$ on the memory knowledge representation and the process of deficiency.

He has actively participated in the management of responsibilities at Universitat de Lleida (Director of the Department of Pedagogy and Psychology, vice-Dean of the Universitat de Lleida, ...).

Both authors are members of the Cognition and TIC (COnTIC) official research group. We thank the funding of the UdL's projects MQD-2006 A and B modalities.

\section{INTRODUCTION}

Information and communication technologies (ICT) are tools that can be found nowadays in almost all the institutions of our society. ICT is being used in the educational field as a resource with a great potential of capacities and uses that provide multiple learning and evaluation methodologies. Recently, there has been an increase of virtual campuses as educational institutions see virtual campuses as a helpful resource for teaching and learning processes.

One of the most interesting contributions of ICT is the possibility to communicate in a virtual and asynchronous way. Multiple researchers have studied the possibility that the interactivity with peers and social nets in learning have facilitated the learning process.

As Black (2002) has proposed, a virtual classroom should have two objectives: on the one hand, facilitating advanced educative experiences more fluidly among students and, on the other hand, increasing the effectiveness and the quality of the education through collaborative learning processes helped by ICT.

According to Dewiyanti et al. (2007), these virtual environments let students exchange information and work all together thinking their own ideas in a critical way, so that they can negotiate them with their peers and reach conclusions.

Without any doubt, the fact of setting adequate communicative channels among participants is a vital aspect in order to foster successful interactivity and a significant exchange of informa- 
tion.

Nevertheless, the possibilities that collaborative learning offers are not easy to put into practice. It is necessary to bear in mind that the basic factors to guarantee the success of CSCL processes are many and very different, ranging from aspects related to personality (Addison and Hutcheson, 2001), to popularity among students and learning features (Prinsen, Volman and Terwel, 2007). Therefore, observing all these multiple aspects and features, selecting a set of knowledge becomes very important Veermans and Cesareni (2005).

The aim of this study is to explain the research that has been done with virtual forums in the collaborative environment Knowledge Forum. Thirty forums of different subjects from the University of Lleida have been analyzed.

This paper examines specifically the variability of pedagogical uses in the Knowledge Forum, tries out the viability of a set of methodological resources in order to analyze asynchronous forums and esteems when authentic collaborative knowledge processes take place. First of all, students had been asked to answer a preliminary questionnaire through which data about their ability for using programs and students’ attitudes towards ICT was gathered. Secondly, students participated in forum activities. The resulting data was analyzed in both quantitative and qualitative ways. Quantitatively, we collected the number of messages, the number of students, the number of participants, the number of words, the tutor messages, the student messages, the number of original messages, the number of threads and the number of messages existent for each thread. Qualitatively, the content of every message has been analyzed too. Taking the idea as the unit of analysis, messages have been analyzed at two levels: on the one hand, as a set of knowledge building process categories and on the other hand, following the scaffolds given in the collaborative virtual environment Knowledge Forum. Both category systems are explained in this article. Finally, the results and conclusions reached are shown. 


\section{ConteXt AND METHODOLOGY}

\subsection{Computer Supported Collaborative Learning (CSCL)}

Knowledge has been always considered, up until a few years ago, as an individual process. With the introduction of ICT in learning processes this idea of a student getting information given by a teacher in a classroom has become obsolete. When elements like ICT, collaboration, e-learning, blended learning and so on, are included in education, we must change our perspective on teaching and the learning processes. One of the most important changes is that, now, each student participates actively of his or her learning process, and the teacher takes a second place, guiding and helping, but always considering that students must have an active role.

Both blended learning and e-learning are very important in order to increase and improve the teaching and learning processes. Collaborative learning has a crucial influence on these learning processes and as Black (2002) states, group working facilitates a lot the task of learning problem and complex task solving. Moreover, collaborative learning implies that: first, students work collaboratively on shared activities; second, students develop responsibility while they are carrying out shared activities; and third, they exchange information in order to build up shared knowledge. This knowledge, obtained after a collaborative task, improves individual learning processes.

Having mentioned the advantages of collaborative learning and bearing them in mind together with ICT, we could reach high-quality collaborative virtual learning processes. As an upshot of this match between collaborative learning and ICT, what results is called CSCL. 
The acronym CSCL has its origin in the First International Conference on CSCL - University of Indiana 1995- where the educational science discipline referred to computer supported collaborative learning is first found (Koschmann, 1996). Following the contextualization done by Van Drie, Van Boxtel and Van der Linden (2006), CSCL is defined as: a learning environment that allows easy access to information and in which individuals can share knowledge and/or build knowledge through communication and interactivity.

The aim of this knowledge building requires the following aspects: that the student has the responsibility or the control of the knowledge building processes, that the student understands that knowledge is a continual process of building ideas, to have a technology which helps to make transparent and explicit the ideas so that they can be improved, to have social approval in knowledge creation and to have a knowledge building community net (Scardamalia, 2004).

In figure 1 the circuit of the social construction of knowledge implies that two or more individuals explain their ideas and publish them. While a debate is being developed, different points of view are enriched and participants can reach a final idea which becomes the object of knowledge. Hence, the building of knowledge as a learning object is very important because students create shared contents.

Collaborative learning - which includes the use of tools in order to foster virtual participation (De Wever et al., 2006) - goes beyond the acquisition of knowledge through individual learning, becoming a collaborative construction. However, the interrelation between learning and technology may arise complex situations (Stahl, Koschmann and Suthers, 2006).

This implies that students must express their thoughts (ideas, opinions) and they must also take into account the points of view of others. Hence, there are cognitive and social conflicts 
which should be solved by each student. This interactivity means rich educative experiences that help students observe and analyze their environment in a more objective way. Moreover, these experiences improve the students’ participation in more significant cognitive activities. The individual advantages that the collaborative learning brings go beyond the academic context. Students acquire new skills and knowledge and with them they can easily develop further in other contexts. For instance, social skills used in virtual forums can be useful for students in future working environments.

As it has been mentioned in the introduction of the present article, we have taken the idea as the unit of the qualitative analysis. Thus, a message or a note can have more than one idea. Different authors have also taken the idea as the unit of analysis, for instance Salovaara (2005), Strijbos (2006) and De Smet, Van Keer and Valcke (2008). When we decided to take it as the center of the analysis, we realized that there were different studies which considered other units of analysis. For example Timmers et al, 2008; Veermans and Cesareni, 2005; Bonnett et al, 2006; Zemel et al., 2007; Valcke, 2006, have incorporated the whole message. De Wever et al., 2006 centered on topics and Cacciamani andFerrini (2007) took as the unit of analysis a sentence limited by punctuation mark.

\subsection{Aims}

- To explore the variability of pedagogical uses which take place in the same asynchronous environment (Knowledge Forum).

- To try the viability of a set of methodological resources in order to analyze asynchronous forums.

- To estimate when processes of authentic collaborative knowledge building take place. 


\subsection{The research context}

At Lleida University, the Support Area to Innovation and e-Learning, which belongs to Educational Science Institute, is responsible for the introduction of ICT in the teaching and learning processes. Psychological and pedagogical aspects are used in order to create virtual quality learning.

Forums analyzed have been done in the collaborative virtual environment named Knowledge Forum. There have been multiple researchers who have done studies and research about CSCL in this collaborative environment. For example, De Laat (2000), Dillenbourg et al. (2001), Rahikainen et al. (2001), Kleine et al. (2002), Salovaara and Järvelä (2003), Russell and Perris (2003), Hakkarainen (2004), Salovaara (2005), Prinsen et al. (2007), Cacciamani and Ferrini (2007).

Ideas are the center of knowledge construction and they can be shown as a text, a graphic, a video or a drawing, and they constitute a Note, central unit of the analysis.

Notes can be catalogued depending on the type of communication (in a knowledge building speech or in an opinion speech). This label or scaffold is a helpful element in the process by which students show their ideas to others. This scaffolding process can be created for every database and it also facilitates ideas about how roles can be defined in the construction of critical thinking. Finally, the environment has resources to foster awareness through several indicators about individuals’ participation in the group.

\subsection{Development}

First of all, participants answered a preliminary questionnaire. The reliability and validity of the questionnaire were studied beforehand, Verdú (2009). Furthermore, the pedagogic context 
where the forums took place was analyzed through semistructured interviews to professors.

Secondly, thirty forums of different university studies have been analyzed. The total number of participants was 644. Knowledge Forum has its own analytic tools which allow to gather quantitative data from the content of the forums. These tools facilitate the collection of data following the creation of notes and views, the notes that have been read by subjects, and so on.

There are also analytic tools which make it easier to analyze the vocabulary used and to gather and relate the interactivity among participants.

Finally, a qualitative analysis of the content was done. It consisted of a categorization of the message content using a category system (with a high level of reliability) Verdú (2009).

\section{Results}

\subsection{Pedagogic usage of the forums}

The thirty forums analysed are different among themselves in the procedure they have followed. As it can be seen in figure 2, in some forums, students were in groups of three or four participants and they had to develop a group activity entailing a final product. They were made aware that both procedure (knowledge building) and their production were being assessed.

In other forums students only exchanged information with the rest of the students and they weren't asked to carry out a final task. Therefore, only the procedure was being assessed. Instructions given at the beginning of a forum are very important, because a well-explained activity can be decisive for the forum's success. Not only have students a reference about what 
they are expected to do, but they can also guess the aims of the forum and the knowledge they will have to build in it. Thus, the guidelines are crucial and they can be put forward as a question, a statement, an example, and so on. 3 of the analyzed forums do not have instructions and students have started them freely, the only information being the title of the forum. 9 forums of the ones analyzed have a specific topic, but they do not have a research question. And the rest of the forums analyzed, 18, have both instructions and a specific topic. Guidelines established by the tutor in order to guide the communication exchange are very interesting. Authors like Van Drie et alt (2005) have stated that these guides must be flexible, because if they are too rigid, they can hinder spontaneity and the conversation rhythm. At the same time, however, guidelines cannot be too open, because then, we can lose sight of the initial aims of the forum and new and different topics would arise. In the forums that we have analyzed we can observe that only 13 of them have been guided and 17 have not. Thus, only 45\% have guides, and 55\% don't have any kind of instructions, which is an important fact to take into account for the forum analysis.

The motivational design of a forum is very important, because it helps successful communication and promotes a high level of quality, Salovaara (2005). In the forums analyzed we observe that 18 out of the 30 forums do not have it.

Furthermore, it is very important to assess forum activity and make it an important part of the final mark of the subject, because if it is not evaluated, students will not participate with the same level of implication. There are only 4 forums out of the 30 analyzed that did not take the forum into account in the subjects' final evaluation.

Besides, previous experience in virtual forums is another crucial factor that must be taken into account. There are two possibilities: at the one end of the spectrum, students have experienced 
virtual forums because they have participated in other subjects. At the other end of the spectrum, students have participated in a mock virtual forum before taking place in the first official virtual forum in the same subject. Results show that 14 forums out of the 30 analyzed had developed previous procedures and students from 16 forums had already participated in a previous one.

Now we have explained the characteristics of the subject research, we can proceed to expose data from previous questionnaires.

Answers from questionnaires reveal clear data to us worth analysing. Data from table 1 show us that students use the computer, basically as a tool for writing and for sending e-mails.

Picture programs are less used than text processor programs. $19.5 \%$ of the students need help in order to use these picture programs and $4.3 \%$ confirm that they have never used them at all.

The same happens with the usage of online database, $60 \%$ of students say that they search information in the Internet, but $27.6 \%$ of them need help for doing this search and $13.3 \%$ of students have never done it before.

Gathered data about students' attitudes about ICT show us a positive attitude towards it. As it can be observed in table 2, $80 \%$ of students state that ICT can improve their knowledge and $88 \%$ of them think that working in small groups is a good methodology and $62 \%$ say that ICT allows for communication among students and consequently, they can share experiences.

Once students had participated in forum activities and data was gathered, both quantitative and qualitative analysis was done.

After gathering the number of messages, the number of words of each forum and the number 
of threads, in table 3 it can be observed that participation was very different in all the analyzed forums.

It can be appreciated, that the decrease in students enrolled, and students who have participated in forums effectively, can be caused by different factors. Firstly, subject aspects need to be borne in mind, such as methodology, forum topic or the tutor's role. Secondly, students are different among themselves in level of knowledge of ICT, in their ideas, in their points of view and so on. Finally, the teaching and learning setting is unique in every case.

As it can be observed in table 4, tutor participation is lower than students participation. This fact can reflect the change of role established with ICT, where students are more active and the tutor is the mediator of their learning process.

The number of, both, original and non-original (answers) notes have been gathered as it is shown in table 5. In order to collect data and to be able to analyze message threads in every forum, we have taken original messages and we have counted all messages included in each one. Every arrow indicates a different thread. Threads made in every forum reflect the diversity among forums, having more than 20 threads in forums 6,7,10 and only one in $1,2,3,4,17,18,19,20,21,22,23,24,25,26,27,30$.

\subsection{Qualitative analysis of forum contents}

The content of every message is analyzed in a qualitative way. In order for us to be able to do category analysis, messages were copied in a text processor and they were analyzed. The unit of analysis is the idea. This qualitative analysis of messages written by students has been done in two levels: first of all, according to the set of knowledge building process categories, which 
was created taking into account Stahl's theory (2000) as it can be seen in table 6 .

Once we have analyzed all messages in a text processor, we have counted how many categories have been used by every student and tutors. Besides, categories have been compared in order to establish the similarities and differences among them.

Regarding the set of knowledge building processes categories as a first level of analysis, we have also analyzed the data according to the categories (scaffolds) proposed by the Knowledge Forum environment, following Scardamalia (2004), which is the second level of analysis. There are two groups of categories: opinion (different opinion, reason, elaboration, evidence, example and conclusion) and knowledge building (I need to understand, new information, this theory cannot be explained and put knowledge together).

Under the same note or message, we can find several categories, because, as we have explained earlier, the unit of analysis is the idea. Hence, above all in long notes, we can find several categories of different levels. In table (table 7), the equivalence established between Collaborative knowledge construction process and Knowledge Forum categories can be observed.

As it can be observed in figure 3, where the set of knowledge building processes categories are shown, explanation is the most used category. Subjects write their opinions in forums without reading other notes and consequently, there is not interactivity or discussion. What they simply do is transmitting their own ideas and points of view.

The second used category is clarification. This can be referred to an individual or group clarification. Students can give evidence, examples and/or reasons to their peers. However, 
this kind of group clarification sometimes is not the answer of a question or a demand, but it is an individual elaboration with the main aim of demonstrating to others, and especially to the teacher, their own knowledge about the topic of the forum.

Data obtained from Knowledge Forum categories make us aware of the fact that these ones are similar to Stahl's. These results are shown in figures 4 and 5, one of them with knowledge building categories and the other with opinion categories.

\section{Conclusions}

According to students, their knowledge about ICT is high. Although there are programs that are not used and students affirm that they do not know them very well, generally ICT is valued positively.

The pedagogic uses of the collaborative environment Knowledge Forum in the three subjects analysed is not regular: it is different in substantial aspects as for example the role of the tutor, the motivational design and knowledge objects building.

What is considered a clue issue for CSCL is giving scaffolding throughout the activity, that is, if students have doubts and they need help, they can obtain answers and explanations so that they can solve them. Successful networking is another crucial aspect to avoid students' frustration or impatience and the feeling that they are wasting their time.

From our point of view, in order to analyze participation in forums, it is necessary to adopt a multiple methodological approach. Even though quantitative data show us that the level of participation is high, we cannot be so optimistic. As it is shown in table 3, it is necessary that 
students have a high level of motivation to foster participation because some of them have hardly participated in forums.

Qualitative analysis of message content according to Stahl shows us that categories from first levels (explanation and clarification) are the most used. Discussion, negotiation and conclusion are less used and on occasions they do not appear in the forum. Something similar happens in Kwnoledge Forum categories. In spite of the fact that there are a lot of messages referred to opinion and clarification categories or scaffolds, it is observed that there are very few messages with different opinions, asking for help, negotiating or concluding. These results are similar to those observed in the spontaneous usage of specific developed environments for collaborative knowledge building (Sanuy and Verdú, 2005) and (Sanuy and Verdú, 2006).

In this way, we have to consider that what is done in virtual forums mainly is to transmit information. Most participants only wrote their contribution without reading any other. They give personal points of view and opinions to others, including on certain occasions examples, evidence and elaborations. There is a lack of interactivity in which students ask doubts, expose problems, suggestions, and explain different ideas to those exposed previously in a reasonable way and with foundation. One possible explanation for these results is the lack of interest and motivation to read and think about other colleagues' messages and ideas.

Seeing these results, it is possible to reach a conclusion: the participation in virtual teaching and learning environments does not guarantee collaborative knowledge building. Nevertheless, it is very important to enhance the pedagogic usage that technological tools offer us. 
In order to optimize the use of virtual forums, a key element seems to be the disposition of tools which enhance familiarity and motivation in order to exchange information with other participants and improve the level of discussion. This depends on cognitive, social, emotional, motivational and contextual variables (Häkkinen, 2004).

To optimize the usage of collaborative environments implies, first of all, the need to increase participation. Secondly, interactivity should be more significant. What we mean is that the exchange of information and the discussion interaction needs to be enhanced. And finally, interactivity needs to allow students to go further in group comprehension and in the formalization of shared knowledge.

This optimization suggests mainly three elements: to have similar interests among participants, to coordinate tasks and to take into account tutor actions. Therefore, in the first place, the group should establish several aims among all participants (for example to elaborate a knowledge object) and, in this way, participants would feel close to others, socially and emotionally (Kirschener and Van Bruggen, 2004). In the second place, it is important to achieve understanding about how they will carry out tasks, in what way they can achieve aims and establish coordination mechanisms.

The design of appropriate kinds of discourses and the usage of catalogued notes that can be observed in Knowledge Forum are resources, which are necessary, but not enough, for going further from simple explanation.

And thirdly, the tutor is also a clue character, (Black, 2002) since he/she brings a clear and concrete explanation to students referring to what they have to do. In this way, the tutor familiarizes students with the virtual environment, and advise them about adequate strategies 
to use. The tutor can also introduce metacognitive and self-regulation scaffolds during the activity process and obviously in the moment of assessing educative experiences.

\section{REFERENCES}

Addison, P. A. and Hutcheson, V. K. (2001). The importance of prior knowledge to new learning. Teaching and learning forum 2001. http://lsn.curtin.edu.au/tlf/tlf2001/addison.html (accessed 24/11/08)

Black,G. (2002). Student assessment of virtual teams in an online management course. Journal of business administration online, 1 (2)

Cacciamani, S; Ferrini, T (2007). Costruire conoscenza in un corso universitario on line è davvero possibile? TD40 numero 1-2007, 28 - 36

De Laat et alt (2000). Supporting a community of practice: the role of workers as learners. Paper presented at Ed-Media, Montreal, Canada June 26-July 1, 2000

De Wever, B., Schellens, T., Valcke, M., \& Van Keer, H. (2006). Content analysis schemes to analyze transcripts of online asynchronous discussion groups: A review. Comput.Educ., 46(1), 6-28.

Dewiyanti, S., Brand-Gruwel, S., Jochems, W., \& Broers, N. J. (2007). Students' experiences with collaborative learning in asynchronous computer-supported collaborative learning environments. Comput.Hum.Behav., 23(1), 496-514. www.sciencedirect.com (accessed 28/04/08)

Dillenbourg, P; Eurelings, A; \& Hakkarainen, K. (2001) Beyond "Sitting Next to Each Other": A Design Experiment on Knowledge Building in Teacher Education. Proceedings of the first European conference on computer-supported collaborative learning, Maastricht, March 22-24, 2001 (pp. 20-28).

Hakkarainen, K. (2004). Emergence of Progressive-Inquiry Culture in Computer-Supported Collaborative Learning. Learning Environments Research 6: 199-220, 2003. Kluwer Academic Publishers. Printed in the Netherlands. 
Häkkinen, P. (2004). What makes learning and understanding in virtual teams so difficult? Cyberpsychology \& Behaviour, Volume 7, Number 2, pp. 201-206.

doi:10.1089/109493104323024465

Kirschener, P., \& Van Bruggen, J. (2004). Learning and understanding in virtual teams. Cyberpsychology \& Behaviour Volume 7, Number 2,

Kleine, J; De Laat, M van der Meijden, H. (2002). Seeking attunement in collaborative learning. Paper presented at ISCRAT 2002, Ámsterdam

Koschmann, T. (1996). CSCL: Theory and practice of an emerging paradigm Lawrence Erlbaum Associates, Inc

Prinsen, F., Volman, M. L. L., \& Terwel, J. (2007). The influence of learner characteristics on degree and type of participation in a CSCL environment. British Journal of Educational Technology, 38(6), 1037-1055. doi:10.1111/j.1467-8535.2006.00692.x

Rahikainen, M., Lallimo, J., \& Hakkarainen, K. (2001). Progressive inquirí in CSILE environment: teacher guidance and students' engagement. http://www.helsinki.fi/science/networkedlearning/texts/rahikainenetal2001. (accessed 09/12/08)

Russell, A; Perris, K. (2003). Telementoring in Community Nursing: a shift from dyadic to communal models of learning and professional development. Mentoring and Tutoring, Vol. 11, No. 2, August 2003

Salovaara, H., \& "Järvelä, S. (2003). Student's strategic actions in computer-supported collaborative learning. Learning Environments Research, pp. 267-285. Learning Environments Research http://www.springerlink.com/content/u1l5125114738621/fulltext.pdf (accessed 21/11/08)

Salovaara, H. (2005). An exploration of students' strategy use in inquiry based computersupported collaborative learning. J.Comput.Assisted Learn., 21(1; 1), 39-52. Journal of Computer Assisted Learning Periodical, Abbrev:J.Comput.Assisted Learn. Pub Year:2005 Pub Date Free Form:02 Volume:21 Issue:1 Start Page:39 Other Pages:52

Sanuy, J; Verdú. N (2005) Construcción colaborativa de conocimientos por parte de estudiantes universitarios, mediante un programa informático de aprendizaje colaborativo. IV Jornadas de desarrollo humano y educación. Alcalá de Henares. 
Sanuy, J; Verdú, N (2006) Anàlisi i comparativa quantitativa i qualitativa de fòrums virtuals realitzats a dos plataformes diferents (WebCT i Sakai) als primers quadrimestres dels cursos 2004/05 i 2005/06 a la Universitat de Lleida". Al "IV Congrés Internacional: Docència Universitària i Innovació”. Barcelona 5, 6 i 7 de juliol de 2006.

Scardamalia, M. (2004). CSILE/Knowledge Forum. In Education and technology: An encyclopedia (pp. 183-192). Santa Barbara: ABCCLIO.

Stahl, G. (2000). A model of collaborative learning. Fourth Internacional Conference of the Learning Sciences (pp. 70-77). Mahwah, NJ: Erlbaum.: Retrieved from http://www.umich.edu/ icls/proceedings/pdf/Stahl.pd (accessed 01/02/08)

Stahl, G., Koschmann, T., \& Suthers, D. D. (2006). Computer-supported collaborative learning. In R. K. Sawyer (Ed.), The cambridge handbook of: The learning sciences. (pp. 409425) Cambridge University Press.

Van Drie, J., van Boxtel, C., Jaspers, J., \& Kanselaar, G. (2005). Effects of representational guidance on domain specific reasoning in CSCL. Comput.Hum.Behav., 21(4), 575-602.

Van Drie, J., van Boxtel, C., \& van der Linden, J. L. (2006). Historical reasoning in a computer-supported collaborative learning environment. In A. M. O'Donnell, C. E. HmeloSilver \& G. Erkens (Eds.), Collaborative learning, reasoning, and technology. (pp. 265-296) Lawrence Erlbaum Associates Publishers.

Veermans, M., \& Cesareni, D. (2005). The nature of the discourse in webbased collaborative learning environments: Case studies from tour different countries. Comput.Educ., 45(3), 316336.

Verdú, N. (2009). Entornos de enseñanza y aprendizaje virtuales en la docencia universitaria: el aprendizaje colaborativo mediado por ordenador. Tesis doctoral. Departamento de pedagogía y psicología. Universidad de Lleida. 


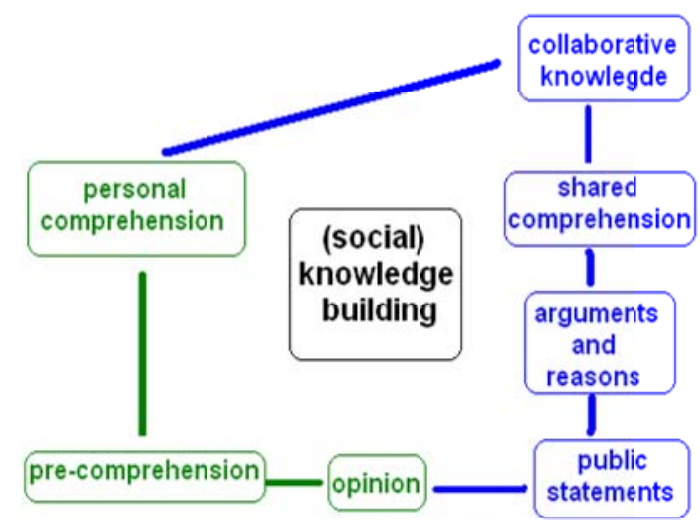

Figure 1. A set of knowledge building process categories

Figure 2: Forum evaluation

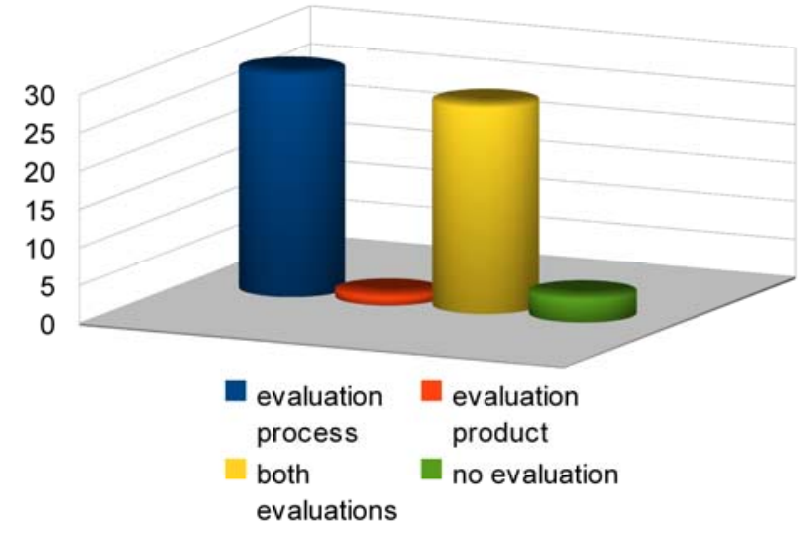




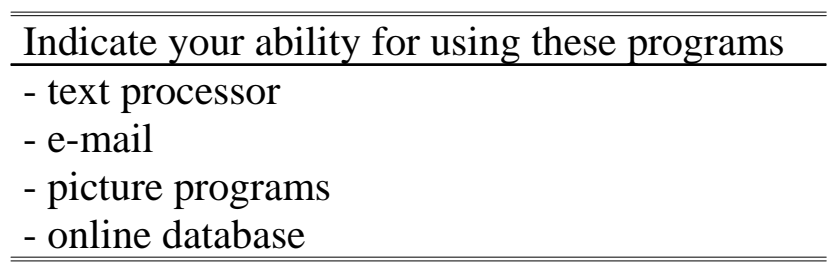

Table 1: Level of autonomy in using tools

Tick those items which are relevant for you to indicate your agreement with the following statements

- I think that ICT can improve my knowledge

- I feel comfortable working in a group

- I would like to share information and ideas with people with whom I have similar interests

- ICT allows sharing personal experiences in an effective way

- I like working with a computer in small groups

Table 2: Attitudes towards ICT

\begin{tabular}{|c|c|c|c|c|c|c|}
\hline Subject & $\begin{array}{c}\text { Number of } \\
\text { students }\end{array}$ & $\begin{array}{c}\text { Number of } \\
\text { participants }\end{array}$ & Messages & $\begin{array}{c}\text { Tutor mes- } \\
\text { sages }\end{array}$ & $\begin{array}{c}\text { Students mes- } \\
\text { sages }\end{array}$ & $\begin{array}{c}\text { Number of } \\
\text { words }\end{array}$ \\
\hline Max & 85 & 114 & 300 & 39 & 266,00 & $50.239,00$ \\
\hline Min & 6 & 6 & 12 & 0 & 11,00 & 960,00 \\
\hline MEAN & 31,27 & 25,70 & 73,73 & 8,67 & 61,73 & $10.921,27$ \\
\hline SD & 21,85 & 24,81 & 71,72 & 11,25 & 60,24 & $13.387,61$ \\
\hline
\end{tabular}

Table 3: Forum participation 


\begin{tabular}{|c|c|c|c|}
\hline Subject & Messages & $\begin{array}{c}\text { Tutor } \\
\text { messages }\end{array}$ & $\begin{array}{c}\text { Student } \\
\text { messages }\end{array}$ \\
\hline Max & 300 & 39 & 266,00 \\
\hline Min & 12 & 0 & 11,00 \\
\hline MEAN & 73,73 & 8,67 & 61,73 \\
\hline SD & 71,72 & 11,25 & 60,24 \\
\hline
\end{tabular}

Table 4: Tutor and student messages

\begin{tabular}{|c|c|c|c|}
\hline Subject & Original messages & Threads & Messages for each thread \\
\hline 1 & 1 & 1 & 62 \\
\hline 2 & 1 & 1 & 36 \\
\hline 3 & 1 & 1 & 56 \\
\hline 4 & 1 & 1 & 93 \\
\hline 5 & 175 & 15 & $2 / 2 / 2 / 2 / 3 / 2 / 2 / 2 / 2 / 2 / 2 / 2 / 2 / 2 / 2$ \\
\hline 6 & 169 & 25 & $\begin{array}{c}2 / 3 / 2 / 2 / 2 / 2 / 2 / 2 / 2 / 2 / 2 / 2 / \\
2 / 2 / 2 / 2 / 2 / 2 / 2 / 3 / 2 / 2 / 2 / 2 / \\
2\end{array}$ \\
\hline 7 & 170 & 30 & $\begin{array}{l}\rightarrow 2 \rightarrow 2 \rightarrow 2 \rightarrow 2 \rightarrow 2 \rightarrow 2 \rightarrow 2 \rightarrow \\
2 \rightarrow 2 \rightarrow 2 \rightarrow 2 \rightarrow 2 \rightarrow 2 \rightarrow 2 \rightarrow 2 \\
\rightarrow 2 \rightarrow 2 \rightarrow 2 \rightarrow 3 \rightarrow 2 \rightarrow 2 \rightarrow 2 \rightarrow \\
2 \rightarrow 2 \rightarrow 2 \rightarrow 2 \rightarrow 2 \rightarrow 2 \rightarrow 2 \rightarrow 2\end{array}$ \\
\hline 8 & 34 & 4 & $\rightarrow 2 \rightarrow 2 \rightarrow 2 \rightarrow 2$ \\
\hline 9 & 14 & 5 & $6 / 2 / 2 / 2 / 2$ \\
\hline 10 & 257 & 36 & $\begin{array}{l}\rightarrow 2 \rightarrow 2 \rightarrow 2 \rightarrow 2 \rightarrow 2 \rightarrow 2 \rightarrow 3 \rightarrow \\
2 \rightarrow 2 \rightarrow 2 \rightarrow 2 \rightarrow 2 \rightarrow 2 \rightarrow 2 \rightarrow 2 \\
\rightarrow 3 \rightarrow 2 \rightarrow 4 \rightarrow 2 \rightarrow 2 \rightarrow 2 \rightarrow 3 \rightarrow \\
2 \rightarrow 2 \rightarrow 2 \rightarrow 2 \rightarrow 2 \rightarrow 2 \rightarrow 2 \rightarrow 2\end{array}$ \\
\hline
\end{tabular}




\begin{tabular}{|c|c|c|c|}
\hline & & & $\rightarrow 2 \rightarrow 2 \rightarrow 2 \rightarrow 2 \rightarrow 2 \rightarrow 4$ \\
\hline 11 & 162 & 15 & $\begin{array}{l}\rightarrow 2 \rightarrow 2 \rightarrow 2 \rightarrow 2 \rightarrow 2 \rightarrow 2 \rightarrow 2 \rightarrow \\
2 \rightarrow 2 \rightarrow 5 \rightarrow 2 \rightarrow 2 \rightarrow 2 \rightarrow 2 \rightarrow 2\end{array}$ \\
\hline 12 & 36 & 10 & $\begin{array}{c}\rightarrow 3 \rightarrow 2 \rightarrow 2 \rightarrow 2 \rightarrow 2 \rightarrow 2 \rightarrow 2 \rightarrow \\
2 \rightarrow 2 \rightarrow 3\end{array}$ \\
\hline 13 & 34 & 8 & $\begin{array}{c}\rightarrow 2 \rightarrow 2 \rightarrow 2 \rightarrow 4 \rightarrow 2 \rightarrow 3 \rightarrow 2 \rightarrow \\
2\end{array}$ \\
\hline 14 & 33 & 10 & $\begin{array}{c}\rightarrow 3 \rightarrow 2 \rightarrow 3 \rightarrow 2 \rightarrow 2 \rightarrow 2 \rightarrow 2 \rightarrow \\
2 \rightarrow 2 \rightarrow 2\end{array}$ \\
\hline 15 & 51 & 11 & $\begin{array}{c}\rightarrow 2 \rightarrow 3 \rightarrow 2 \rightarrow 2 \rightarrow 2 \rightarrow 2 \rightarrow 2 \rightarrow \\
2 \rightarrow 2 \rightarrow 2 \rightarrow 2\end{array}$ \\
\hline 16 & 36 & 6 & $\rightarrow 3 \rightarrow 2 \rightarrow 2 \rightarrow 2 \rightarrow 2 \rightarrow 2$ \\
\hline 17 & 1 & 1 & 12 \\
\hline 18 & 1 & 1 & 24 \\
\hline 19 & 1 & 1 & 17 \\
\hline 20 & 1 & 1 & 17 \\
\hline 21 & 1 & 1 & 14 \\
\hline 22 & 100 & 1 & 1 \\
\hline 23 & 1 & 1 & 39 \\
\hline 24 & 1 & 1 & 45 \\
\hline 25 & 1 & 1 & 35 \\
\hline 26 & 1 & 1 & 26 \\
\hline 27 & 1 & 1 & 50 \\
\hline 28 & 119 & 16 & $\begin{array}{c}\rightarrow 5 \rightarrow 2 \rightarrow 2 \rightarrow 2 \rightarrow 2 \rightarrow 2 \rightarrow 2 \rightarrow \\
2 \rightarrow 2 \rightarrow 2 \rightarrow 4 \rightarrow 2 \rightarrow 2 \rightarrow 2 \rightarrow 4 \\
\rightarrow 3\end{array}$ \\
\hline 29 & 3 & 7 & $\rightarrow 2 \rightarrow 1 \rightarrow 1 \rightarrow 1 \rightarrow 2 \rightarrow 1 \rightarrow 1$ \\
\hline 30 & 1 & 1 & 57 \\
\hline
\end{tabular}

Table 5: Message threads 


\begin{tabular}{l|l}
\hline Discussion & Students explain different ideas \\
\hline Clarification & $\begin{array}{l}\text { Students elaborate explanations based on theory, examples and evidences } \\
\text { to explain better their own ideas to other participants. }\end{array}$ \\
\hline Negotiation & $\begin{array}{l}\text { Students propose solutions and other ideas to their classmates in order to } \\
\text { reach a consensus. }\end{array}$ \\
\hline Conclusion & Students reach conclusions through the ideas exposed in forums
\end{tabular}

Conclusion $\quad$ Students reach conclusions through the ideas exposed in forums

Table 6: Collaborative knowledge construction process categories (CKCPC)

\begin{tabular}{l|l|l}
\multicolumn{1}{c|}{ CKCPC } & \multicolumn{1}{|c|}{$\begin{array}{c}\text { Knowledge Forum: knowledge } \\
\text { building }\end{array}$} & \multicolumn{1}{|c}{$\begin{array}{c}\text { Knowledge Forum: } \\
\text { opinion }\end{array}$} \\
\hline Explanation & \multicolumn{1}{|c}{ Opinion (OP) } \\
\hline Explanation & $\begin{array}{l}\text { I need to understand } \\
\text { New information }\end{array}$ & \\
\hline Discussion & This theory can not be explained & Different opinion (DO) \\
\hline Clarification & New information for clarifying & $\begin{array}{l}\text { Reason (RE) } \\
\text { Elaboration (EL) } \\
\text { Evidence (EV) } \\
\text { Example (EX) }\end{array}$ \\
\hline Negotiation & A better theory & \\
\hline Conclusion & Put our knowledge together & Conclusion(CO)
\end{tabular}

Table 7: Relationship between Collaborative knowledge construction process and Knowledge Forum scaffolds categories

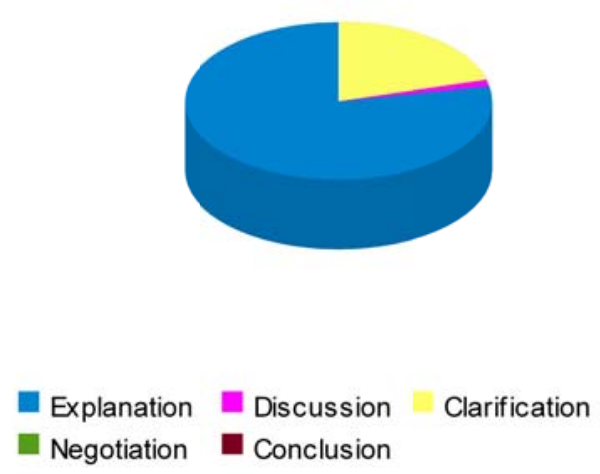

Figure 3 : Results of Collaborative knowledge construction process 


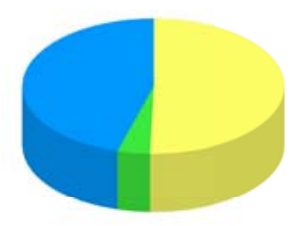

$$
\begin{array}{ccc}
\text { My theory } & \begin{array}{l}
\text { Ineed } \\
\text { understand }
\end{array} & \text { New } \\
\text { inform } & \begin{array}{l}
\text { P better } \\
\text { Put our }
\end{array} \\
\text { theory } & \begin{array}{l}
\text { know ledge } \\
\text { together }
\end{array}
\end{array}
$$

Figure 4: Results of Knowledge Forum Categories: knowledge building

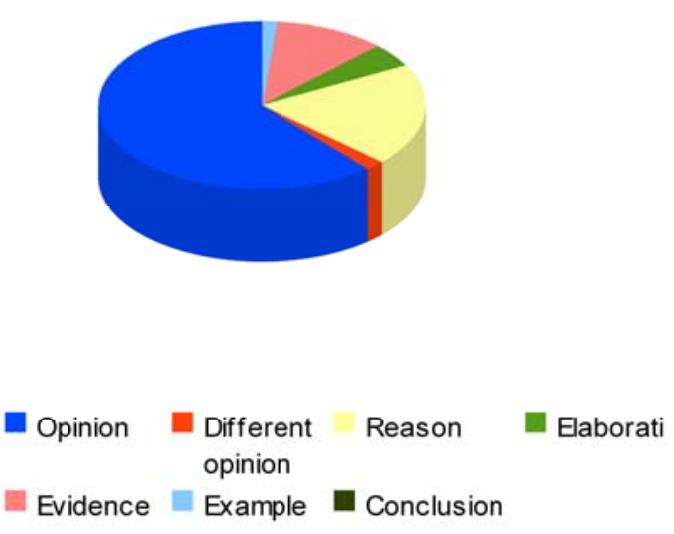

Figure 5: Results of Knowledge Forum Categories: opinion 